\title{
Pathophysiology of Protracted Acute Renal Failure in Man
}

\author{
S. Mark Moran and Bryan D. Myers \\ Division of Nephrology, Stanford University School of Medicine, Stanford, California 94305
}

\begin{abstract}
Postischemic acute renal failure (ARF) induced by cardiac surgery is commonly prolonged and may be irreversible. To examine whether persistence of postischemic, tubular cell injury accounts for delayed recovery from ARF, we studied 10 patients developing protracted (36 \pm 4 d) ARF after cardiac surgery. The differential clearance and excretion dynamics of probe solutes of graded size were determined. Inulin clearance was depressed $(5.0 \pm 1.7 \mathrm{ml} /$ min), while the fractional urinary clearance of dextrans (radii 17-30 $\AA$ ) were elevated above unity. Employing a model of conservation of mass, we calculated that $44 \%$ of filtered inulin was lost via transtubular backleak. The clearance and fractional backleak of technetium-labeled DTPA (199m Tc|DTPA, radius $=4 \AA$ ) were identical to those of inulin (radius $15 \AA$ ). The time at which inulin or DTPA excretion reached a maximum after an intravenous bolus injection was markedly delayed when compared with control subjects with ARF of brief duration, $102 \mathrm{vs} .11 \mathrm{~min}$. Applying a three-compartment model of inulin/DTPA kinetics (which takes backleak into account) revealed the residence time of intravenously administered inulin/DTPA in the compartment occupied by tubular fluid and urine to be markedly prolonged, $20 \mathrm{vs} .6 \mathrm{~min}$ in controls, suggesting reduced velocity of tubular fluid flow. We conclude that protracted human ARF is characterized by transtubular backleak of glomerular ultrafiltrate, such that inulin clearance underestimates true glomerular filtration rate by $\sim \mathbf{5 0 \%}$, and by sluggish tubular fluid flow, which strongly suggests the existence of severe and generalized intraluminal tubular obstruction. Because all patients also exhibited extreme hyperreninemia $(16 \pm 2 \mathrm{ng} / \mathrm{ml}$ per $h)$ that was inversely related to inulin clearance $(r$ value $=-\mathbf{0 . 8 3}$ ) and urine flow ( $r$ value $=-0.70$ ), we propose that persistent, angiotensin II-mediated renal vasoconstriction may have delayed healing of the injured tubular epithelium.
\end{abstract}

\section{Introduction}

A reversible form of acute renal excretory failure has long been known to occur in man in the wake of an episode of transient circulatory failure. Formerly, this postischemic renal injury was characterized by an initial period of oliguria which persisted in the typical case for 7-10 d. Thereafter, a diuretic phase ensued that heralded the onset of a gradual recovery from azotemia over the subsequent $7-10 \mathrm{~d}(1,2)$. This acute renal injury has been accurately simulated in experimental animals by transiently interrupting renal blood flow for 40-60 min. Micropuncture

Address reprint requests to Dr. Myers, Division of Nephrology, S215. Received for publication 7 December 1984 and in revised form 3 June 1985.

J. Clin. Invest.

(c) The American Society for Clinical Investigation, Inc.

$0021-9738 / 85 / 10 / 1440 / 09 \quad \$ 1.00$

Volume 76, October 1985, 1440-1448 studies have revealed that the oliguric phase of postischemic, acute renal failure (ARF) ${ }^{1}$ is caused in large part by intraluminal tubular obstruction accompanied by backleak of a large fraction of glomerular filtrate across a necrotic tubular wall (3-7). As in the human injury, recovery from postischemic ARF in the rat typically begins during the second week after the ischemic insult. It is characterized by an increment in renal perfusion rate, relief of intraluminal obstruction of tubules, and restoration of impermeability of the tubular wall to the small filtration marker, inulin $(7,8)$.

Over the past decade it has become routine practice to administer to susceptible patients protective substances such as mannitol, furosemide, and dopamine before or during an ischemic renal insult. With the adoption of this practice, an isolated single episode of renal ischemia no longer appears sufficient to induce overt renal excretory failure in most instances (9). Rather, more prolonged and often repeated episodes of renal ischemia appear to be required before the clinical syndrome of ARF becomes manifest. A typical example of the latter is that which follows prolonged and difficult cardiac surgery, notwithstanding the use of protective agents (10-12). It occurs in the wake of prolonged cardio-pulmonary bypass ( $\geq 180 \mathrm{~min}$ [13]), during which the kidneys are perfused at a low rate $(\sim 250 \mathrm{ml} / \mathrm{min})$ and at a hydraulic pressure low enough $(\sim 50 \mathrm{mmHg})$ to bring glomerular filtration to a halt (14). Usually this initiating ischemic insult is prolonged and compounded by impaired, postoperative cardiac function $(10,13)$. We have shown previously that only a minority of patients with this form of ARF (21/44) exhibit recovery within 2 wk postinjury. As with the aforementioned experimental analogue of postischemic ARF in the rat, recovery followed circulatory improvement, as manifested by restoration to normal of cardiac performance (10).

Because the phenomenon of postischemic ARF protracted beyond $2 \mathrm{wk}$ has become prevalent and carries a grave prognosis $(13,15,16)$, and because there is no animal model of ARF after prolonged and partial renal ischemia, we have attempted to elucidate directly the functional correlates of this common variant of ARF in man. To do this we studied 10 patients in whom ARF after cardiac surgery was protracted beyond $14 \mathrm{~d}$. We used the excretory dynamics of small filtration markers to examine the role of intraluminal tubular obstruction, and the differential

1. Abbreviations used in this paper: $\mathrm{ARF}$, acute renal failure; $\mathrm{CRF}$, chronic renal failure; $C_{i n}$, inulin clearance; $F_{\mathrm{Na}}$, fractional excretion of sodium; GFR, glomerular filtration rate; $k_{\mathrm{Di}}$, fractional dextran backleak; $k_{\text {in }}$, fractional backleak of inulin; $\theta$, sieving coefficient of the glomerular capillary wall for dextran; $\theta_{\mathrm{app}}$, apparent sieving coefficient for the i'th dextran based solely on plasma and urine concentration measurements; $\theta_{D}$, fractional clearances of narrow dextran fractions; PRA, plasma renin activity; $r_{\mathrm{D}}$, radius of the dextran; $r_{\mathrm{Di}}$, any dextran species of the ith molecular radius; $r_{\text {in }}$, molecular radius of inulin; $T_{\max }$, time after bolus injection when urinary inulin (or DTPA) excretion rate is maximal; $T_{\mathrm{p}}^{*}$, mean residence time of inulin/DTPA in plasma; $T_{u}$, urinary dead space mean residence time; $U_{D S}$, urinary dead space volume; $U / P$, urine-to-plasma; $V$, urine flow rate; $\dot{V}$, rate of urine flow in milliliters per minute. 
clearance of filtration probes of graded size to evaluate transtubular backleak of glomerular filtrate. Our findings reveal a renal injury that is quantitatively more severe than and qualitatively different from human postischemic ARF of shorter duration.

\section{Methods}

Patient population and clinical background. Using a protocol and consent procedure approved by the Stanford University Committee on the Use of Human Subjects in Research, Stanford, CA, we studied 10 patients with satisfactory premorbid renal function who developed protracted ARF subsequent to surgery of the heart and great vessels. There were eight men and two women who ranged in age from 34 to 77 , with a mean ( \pm SE) of $64 \pm 4 \mathrm{yr}$. The development of ARF, initially nonoliguric in all subjects, was manifested by the presence of progressive azotemia accompanied by isosthenuria, and by the increased fractional excretion of sodium $(>1 \%)$ and water (urine-to-plasma inulin concentration ratio $<20$ ) (17). These subjects were selected for study because of unremitting ARF despite several weeks of intensive medical and surgical care. Accordingly, studies of renal physiology were performed $23 \pm 4 \mathrm{~d}$ after the onset of renal excretory failure (Table I).

For comparison, two other groups of subjects were evaluated. These were: (1) Brief ARF group. This group included 32 age-matched patients $(63 \pm 2 \mathrm{yr}), 21$ males and 11 females, in whom ARF resolved within 2 wk. In these subjects, ARF also developed after major cardiac surgery. Studies of renal physiology were performed during a period of increasing azotemia, on average $6 \pm 1 \mathrm{~d}$ after the onset of renal insufficiency. (2) Stable chronic renal failure (CRF) group. This group included 30 patients who had stable CRF of diverse etiology ( $43 \pm 3 \mathrm{yr} ; 15$ males, 15 females).

Hemodynamic findings were similar in protracted and brief ARF (control group 1) populations, as shown in Table II. Mean arterial pressure averaged $74 \pm 3$ vs. $80 \pm 3 \mathrm{mmHg}$, respectively. Mean increase in body weights (compared with admission weights) were identical, $5 \pm 3$ vs. $5 \pm 1 \%$. Large but similar percentages of patients in each group were receiving vasoactive drugs at the time of the studies of renal physiology. In addition, the colloid osmotic pressure of plasma was not significantly different in the two groups, $22.1 \pm 1.0$ vs. $23.3 \pm 0.5 \mathrm{mmHg}$. Measurements of hematocrits also did not significantly differ, $33 \pm 3$ vs. $35 \pm 1 \%$. The cardiac index tended to be low in control subjects with brief ARF $(2.47 \pm 0.12$ liters/min per $\mathrm{m}^{2}$ ). Because appropriate vascular catheters were no longer in place in subjects with protracted ARF, cardiac index could not be determined. The tendency toward a low arterial pressure despite a volumeexpanded state and the administration of dopamine $(n=10)$, and in

Table I. Clinical Features of 10 Patients with Protracted ARF

\begin{tabular}{|c|c|c|c|c|c|}
\hline Patient & Age/Sex & $\begin{array}{l}\text { Day } \\
\text { of study }\end{array}$ & $\begin{array}{l}\text { Day } \\
\text { dialysis } \\
\text { initiated }\end{array}$ & $\begin{array}{l}\text { Day of } \\
\text { recovery }\end{array}$ & $\begin{array}{l}\text { Day } \\
\text { of death }\end{array}$ \\
\hline 1 & $65 / \mathrm{M}$ & 15 & - & 41 & \\
\hline 2 & $34 / \mathrm{M}$ & 25 & 1 & 49 & \\
\hline 3 & $64 / M$ & 16 & 14 & & 29 \\
\hline 4 & $60 / \mathrm{M}$ & 21 & - & 26 & \\
\hline 5 & $77 / M$ & 35 & 33 & & 46 \\
\hline 6 & $49 / F$ & 46 & 44 & & 47 \\
\hline 7 & $77 / \mathrm{F}$ & 25 & 8 & & 30 \\
\hline 8 & $68 / \mathrm{M}$ & 47 & 17 & & 53 \\
\hline 9 & $75 / \mathrm{M}$ & 15 & 12 & & 23 \\
\hline 10 & $73 / \mathrm{M}$ & 14 & - & 14 & \\
\hline Mean & 64 & 23 & 18 & & \\
\hline$\pm \mathrm{SE}$ & \pm 4 & \pm 4 & \pm 5 & & \\
\hline
\end{tabular}

Table II. Hemodynamic Findings in Brief and Protracted ARF

\begin{tabular}{llc}
\hline & Brief ARF & $\begin{array}{l}\text { Protracted } \\
\text { ARF }\end{array}$ \\
\hline $\begin{array}{l}\text { No. patients } \\
\text { Mean arterial pressure } \\
\quad(m m H g)\end{array}$ & 32 & 10 \\
$\begin{array}{l}\text { Colloid osmotic pressure } \\
(m m H g)\end{array}$ & $80 \pm 3$ & $74 \pm 3$ \\
$\begin{array}{l}\text { Increment in body } \\
\text { weight (\%) }\end{array}$ & $23.3 \pm 0.5$ & $22.1 \pm 1.0$ \\
$\begin{array}{l}\text { Hematocrit (\%) } \\
\text { Inotropic agents (\%) } \\
\text { After load-reducing } \\
\text { agents (\%) }\end{array}$ & $55 \pm 1$ & $5 \pm 3$ \\
\hline
\end{tabular}

some cases epinephrine $(n=5)$, suggested that they too manifested a low cardiac output state.

Study protocol. Patients were examined during an episode of ARF that was protracted, as judged by failure of recovery of renal excretory function despite two or more weeks of intensive medical care. All studies were begun $24 \mathrm{~h}$ or more after the most recent hemodialysis treatment when patients were hemodynamically stable and not hypovolemic. Fluid balance was maintained during the study. Clearance studies were performed by giving a single priming dose of inulin $(60 \mathrm{mg} / \mathrm{kg}$ of body weight) and technetium-labeled diethylenetriamine pentaacetic acid ([99m-Tc]DTPA, $1 \mathrm{mCi}$ ). A polydisperse solution of neutral dextran 40 (Rheomacrodex, Pharmacia Fine Chemicals, Uppsala, Sweden, $140 \mathrm{mg}$ / $\mathrm{kg}$ ) was thereafter given by infusion over a 20 -min period. An in-dwelling Foley catheter was used to collect urine specimens. To evaluate the kinetics of filtration marker clearance and distribution within the body, blood and urine specimens were collected during the immediate postprime period at $1,3,5,10,15,30$, and $60 \mathrm{~min}$. Thereafter, clearance studies were commenced with blood and urine collected each half hour for $2 \mathrm{~h}$ and then hourly for an additional 2-4 h. From these plasma and urine samples, the urinary clearances $(C)$ of inulin and DTPA, the fractional excretion of sodium ( $\mathrm{FE}_{\mathrm{Na}}$ ) and the urine-to-plasma $(\mathrm{U} / \mathrm{P})$ osmolality ratio were determined. Clearances were calculated from the ratio $(\mathrm{UV}) /(\mathrm{PT})$, where $\mathrm{U}=$ urinary concentration of the clearance marker, $\mathrm{V}=$ urine flow rate, $\mathrm{T}=$ time of collection, and $\mathrm{P}^{\prime}=\log$ mean of clearance marker concentration in plasma samples bracketing the urine collection. $\left[{ }^{99 \mathrm{~m}} \mathrm{Tc}\right] \mathrm{DTPA}$ was counted in urine and plasma with a Packard gamma scintillation spectrometer (model 3002, Packard Instrument Co., Inc., Downers Grove, IL). The assay of the remaining test solutes employed in the present study has been described in detail previously $(9,10)$. In addition, plasma renin activity (PRA) was determined as the rate of immunoassayable angiotensin I generated in plasma incubated at $\mathrm{pH} 7.4$ and at $37^{\circ} \mathrm{C}(18)$.

After gel chromatographic separation of plasma and urine on precalibrated Sephacryl S-300 columns (Pharmacia Fine Chemicals), the fractional clearances of narrow dextran fractions $\left(\theta_{\mathrm{D}}\right)$ were computed using the equation

$\theta_{\mathrm{D}}=(\mathrm{U} / \mathrm{P})_{\mathrm{D}} /(\mathrm{U} / \mathrm{P})_{\mathrm{IN}}$,

where $(\mathrm{U} / \mathrm{P})_{\mathrm{D}}$ and $(\mathrm{U} / \mathrm{P})_{\mathrm{IN}}$ refer to urine-to-midpoint plasma concentration ratios of dextran and inulin, respectively.

In the two control groups, clearance studies were performed by administering the priming dose followed by a constant infusion of inulin resulting in a steady state plasma concentration. After an equilibration period lasting $60 \mathrm{~min}$, four 30 -min timed urine collections were made and blood was obtained at the beginning and end of each period. Clearances were calculated as reported previously (9-12).

Fractional inulin and dextran backleak. Methods developed in this laboratory to detect and quantitate backleak of uncharged polysaccharides 
(inulin and dextran) from damaged tubules have been reported in detail previously (11). In brief, we have assumed that glomerular permeability to inulin and dextran was not different between patients with protracted ARF and those with CRF in whom inulin clearance was depressed to similarly low levels $\left(<15 \mathrm{ml} / \mathrm{min}\right.$ per $\left.1.73 \mathrm{~m}^{2}\right)$. It follows that any elevation of $\theta_{\mathrm{D}}$ in ARF when compared with $\theta_{\mathrm{D}}$ in CRF might be due to the backleak of inulin through damaged tubules at a greater rate than backleak of the larger filtered dextran molecules. The use of a population with CRF as a control group is novel. It has the advantage that even the smallest component molecules in dextran 40 are retained in serum because of the low glomerular filtration rate (GFR), thus permitting for the first time a comparison between the experimental and control group of the fractional clearance of dextran molecules of radius below $20 \AA$.

When the permeability properties of the tubule are normal, all inulin and dextran cleared by the glomerulus and appearing in the glomerular filtrate is assumed to reach the final urine. It is this assumption that permits estimation of the dextran ultrafiltration characteristics of the glomerular capillary wall (19). For the kidney in ARF, however, we propose that tubule backleak of inulin (and also dextrans) occurs; if we further assume that such leakage is "passive" (that is, occurs solely by ultrafiltration and/or diffusion through the damaged tubule wall), then the rate of leakage of any such solute should be nearly proportional to the concentration of that solute in the glomerular filtrate. Under such circumstances, the fractional backleak of inulin (defined as the rate of backleak divided by the GFR) will be constant $\left(k_{\text {in }}\right)$. Precisely the same criteria apply to any dextran species of the ith molecular radius $\left(r_{\mathrm{Di}}\right)$, leading to a fractional dextran backleak of $k_{\mathrm{Di}}$. However, the permeability of the damaged tubule wall to dextrans would be expected to be a declining function of the size of the dextran molecule,

$k_{\mathrm{Di}}=\mathrm{f}\left(r_{\mathrm{Di}}\right)$,

where $k_{\mathrm{Di}} \rightarrow k_{\text {in }}$ as $r_{\mathrm{Di}} \rightarrow r_{\text {in }} ; k_{\mathrm{Di}} \rightarrow 0$ as $r_{\mathrm{Di}} \rightarrow \infty$. Simple mass-balance computations of inulin and dextran cleared by the glomerulus lead to the following relationship (11):

$\theta_{\text {app }}=\theta\left[1-k_{\mathrm{Di}}\right] /\left(1-k_{\mathrm{in}}\right)=\theta\left[1-\mathrm{f}\left(r_{\mathrm{Di}}\right)\right] /\left(1-k_{\mathrm{in}}\right)$,

where $\theta_{\text {app }}$ is the apparent sieving coefficient for the i'th dextran based solely on plasma and urine concentration measurements, and $\theta$ is the sieving coefficient of the glomerular capillary wall for that dextran. Qualitatively, we can deduce from Eq. 3 that, for large dextran molecules where $k_{\mathrm{Di}} \simeq 0, \theta_{\mathrm{app}}>\theta$ (since [1-k $\left.k_{\mathrm{in}}\right]>0$ ), while for small dextran molecules where $k_{\mathrm{Di}} \simeq k_{\text {in }}, \theta_{\text {app }} \rightarrow \theta$.

Assuming that the dextran sieving characteristics of the glomerular capillary wall in protracted ARF are the same as those in severe CRF, Eq. 3 can be reduced to:

$\theta_{\text {app }} / \theta=\left(1-k_{\mathrm{Di}}\right) /\left(1-k_{\text {in }}\right)=\left[1 /\left(1-k_{\text {in }}\right)\right]-\left[k_{\mathrm{Di}} /\left(1-k_{\text {in }}\right)\right]$,

where $\theta$ now equals the fractional dextran clearance in CRF. Further, $k_{\text {in }}$ is a constant for a given subject, whereas $k_{\mathrm{Di}}$ is a function of $r_{\mathrm{Di}}$. As $r_{\mathrm{Di}} \rightarrow r_{\text {in }}, k_{\mathrm{Di}} \rightarrow k_{\mathrm{in}}$, and as $r_{\mathrm{Di}} \rightarrow \infty, k_{\mathrm{Di}} \rightarrow 0$. Hence, the ratio $\left(\theta_{\text {app }} / \theta\right)$ should increase with $r_{\mathrm{Di}}$ from a value of unity (for small $r_{\mathrm{Di}}$ ) to a limiting value of $1 /\left(1-k_{\text {in }}\right)$ as $r$ increases. Since, as $r \rightarrow \infty, \theta \rightarrow 0$, a plot of $\left(\theta_{\text {app }}\right)$ $\theta)$ vs. $r$ should permit a reasonably accurate extrapolation to the limiting value of $\left(\theta_{\text {app }} / \theta\right) \rightarrow 1 /\left(1-k_{\text {in }}\right)$. This permits calculation of $k_{\text {in }}$.

Since $k_{\text {in }}$ is the fraction of filtered inulin that leaks back,

corrected GFR $=\left[\frac{1}{\left(1-k_{\text {in }}\right)}\right] \cdot \mathrm{C}_{\mathrm{in}}$,

where $\mathrm{C}_{\text {in }}$ denotes inulin clearance.

Measurement of the inulin residence time in the urinary dead space. After the intravenous administration of inulin or DTPA, the filtration marker distributes in plasma, in an extravascular, extracellular space and in a third volume extending from Bowman's space to the urinary bladder (the so-called urinary dead space [20]). There is a delay in the appearance of the injectate in the final bladder urine $(10,20)$. Inulin excretion rises slowly with time, reaches a peak, and then declines pari passu with the falling plasma concentration of inulin. The time required for inulin to traverse the dead space $\left(T_{u}\right)$ and the time required for peak urinary inulin excretion to be observed depend upon several factors. The first is the existence of a pool of tubular fluid and urine known as the urinary dead space, which consists of part or all of the volume of the renal tubules, pelves, and ureters $(10,20)$. Larger dead space volumes (or lower tubular fluid flow rates) will result in a greater delay in inulin appearance and a longer time to peak excretion. The second potential factor affecting both $T_{\mathrm{u}}$ and the time to peak urinary inulin excretion is leakage of glomerular filtrate across the damaged renal tubular epithelium. If present, backleak decreases net urinary clearance of inulin and, therefore, the apparent GFR as well. A third set of factors affecting $T_{\mathrm{u}}$ is the relationship of plasma volume to apparent GFR and the associated rate of clearance of inulin from plasma into the extravascular space. As plasma volume increases or the rate of extravascular accumulation decreases, $T_{\mathrm{u}}$ prolongs.

We have previously analyzed the kinetics of inulin excretion by devising a 3-compartment model that permits determination of the mean residence time of inulin in plasma and the urinary dead space (10). In the present study we have modified the earlier 3-compartment solution to include the effects of transtubular backleak of the filtered solute. The modification yields the following formulation:

$\left(T_{\max }\right)^{-1}=\left(\left(T_{\mathrm{u}}\right)^{-1}-\left(T_{\mathrm{p}}^{*}\right)^{-1}\right) /\left(\operatorname{Ln}\left[\left(T_{\mathrm{p}}^{*} / T_{\mathrm{u}}\right)\right]\right)$.

$T_{\max }$, time after bolus injection when urinary inulin (or DTPA) excretion rate is maximal. $T_{\mathrm{u}}$, urinary dead space mean residence time where $T_{\mathrm{u}}$ $=\mathrm{U}_{\mathrm{DS}} \cdot \dot{V} ; \mathrm{U}_{\mathrm{DS}}$ is the volume in milliliters of the dead space and $\dot{V}$ is the rate of urine flow in milliliters per minute. $T_{\mathrm{p}}^{*}$, mean residence time of inulin/DTPA in plasma. It is determined by the plasma volume and by the clearances of inulin or DTPA: $(a)$ from plasma into the urine by glomerular filtration; $(b)$ from plasma into the extravascular space; and finally $(c)$, from tubular fluid back into the vascular and extravascular spaces by the rate of backleak. During ARF, with low urinary excretion rates, $T_{p}^{*}$ is calculated at long times after the bolus injection of inulin/ DTPA, when plasma and extravascular spaces have equilibrated and the "clearance" of inulin or DTPA into the extravascular space is nil. The rate of backleak of a given solute depends upon its molecular size and the extent of increased permeability of the injured tubular epithelium. Thus, $T_{\mathrm{p}}^{*}=$ plasma volume $/\left[\right.$ corrected GFR $\left.\cdot\left(1-k_{\text {in }}\right)\right]$. As backleak increases, net urinary clearance diminishes and the mean plasma residence time rises. Therefore, the time to peak urinary inulin excretion may become substantially prolonged.

Statistical analysis. All results are expressed as mean \pm SEM. Data for the experimental and two control populations were analyzed and compared with the Stat Plus General Statistical Package (Human Systems Dynamics, Northridge, CA). An unpaired two-tailed $t$ test or the MannWhitney $U$ test was used to test the significance of the differences observed. Linear regression analysis was used to examine the strength of associations between variables.

\section{Results}

Clinical and laboratory findings. The results of 10 studies during the course of protracted ARF are shown in Table III and compared with those of 32 subjects having ARF of brief duration. As noted previously, episodes of ARF were lengthy in the experimental group, averaging $36 \pm 4 \mathrm{~d}$ until death supervened or recovery of function was observed. 7 of 10 patients were receiving dialytic support. The profound depression in renal function is indicated by the inulin clearance, which averaged only $5.0 \pm 1.7$, a value significantly less than the corresponding value of $14 \pm 1$ $\mathrm{ml} / \mathrm{min}$ per $1.73 \mathrm{~m}^{2}$ observed in the brief ARF comparison population (control group 1). 5 of 10 patients with protracted ARF were oliguric $(\dot{V} \leq 0.3 \mathrm{ml} / \mathrm{min})$; for all studies, urine flow averaged only $0.6 \pm 0.2 \mathrm{ml} / \mathrm{min}$. Fractional sodium excretion was 
Table III. Laboratory Features of 10 Patients with Protracted ARF

\begin{tabular}{|c|c|c|c|c|c|c|}
\hline Patient & $\begin{array}{l}\mathrm{C}_{\mathrm{in}} \\
\left(\mathrm{ml} / \mathrm{min} / 1.73 \mathrm{~m}^{2}\right)\end{array}$ & $\begin{array}{l}\mathrm{C}_{\text {DTPA }} \\
\left(\mathrm{ml} / \mathrm{min} / 1.73 \mathrm{~m}^{2}\right)\end{array}$ & $\dot{V}$ & $\mathrm{FE}_{\mathrm{Na}}$ & $\begin{array}{l}\mathrm{U} / \mathrm{P} \\
\text { inulin }\end{array}$ & $\begin{array}{l}\mathrm{U} / \mathrm{P} \\
\text { osmol }\end{array}$ \\
\hline & & & $\mathrm{ml} / \mathrm{min}$ & $\%$ & & \\
\hline 1 & 10.0 & 10.0 & 1.4 & 7.1 & 7.0 & 1.2 \\
\hline 2 & 12.0 & 12.0 & 0.5 & 11.5 & 4.0 & 0.8 \\
\hline 3 & 0.4 & 0.4 & 0.07 & 3.3 & 6.0 & 1.0 \\
\hline 4 & 8.0 & 8.0 & 1.1 & 2.7 & 7.0 & 1.0 \\
\hline 5 & 1.0 & 1.0 & 0.3 & 36.6 & 3.0 & 1.2 \\
\hline 6 & 0 & 0 & 0.01 & - & - & - \\
\hline 7 & 1.0 & 1.0 & 0.1 & 1.0 & 8.0 & 1.0 \\
\hline 8 & 1.0 & 1.0 & 0.2 & 6.3 & 7.0 & 0.9 \\
\hline 9 & 2.0 & 2.0 & 0.5 & 3.3 & 6.0 & 1.1 \\
\hline 10 & 15.0 & 14.0 & 1.4 & 0.9 & 11.0 & 1.2 \\
\hline Mean & 5.0 & 4.9 & 0.6 & 8.1 & 7.0 & 1.0 \\
\hline$\pm \mathrm{SE}$ & \pm 1.7 & \pm 1.7 & \pm 0.2 & \pm 3.5 & \pm 0.7 & \pm 0.04 \\
\hline \multicolumn{7}{|c|}{ Nonoliguric ARF of brief duration $(n=32)$} \\
\hline Mean & 14.0 & $\mathrm{ND}^{*}$ & 1.9 & 8.0 & 6.0 & 1.05 \\
\hline$\pm \mathrm{SE}$ & \pm 1.0 & $\mathrm{ND}^{*}$ & \pm 0.4 & \pm 2.0 & \pm 1.0 & \pm 0.05 \\
\hline$P$ value & $<0.05$ & $\mathrm{ND}^{*}$ & $<0.01$ & NS & NS & NS \\
\hline
\end{tabular}

* ND, not done.

elevated $(8.1 \pm 3.5 \%)$; isosthenuria was present (U/P osmolality $1.0 \pm 0.04)$; the urine-to-plasma inulin concentration ratio was low (7 \pm 0.7$)$. All of the foregoing findings are indicative of severe ARF (17). We also compared the clearance of [ ${ }^{99 m}$ Tc]DTPA to that of inulin and found the clearances to be essentially identical, $5.0 \pm 1.7$ vs. $4.9 \pm 1.7 \mathrm{ml} / \mathrm{min}$ per $1.73 \mathrm{~m}^{2}$, respectively.

Measurements of PRA were available in nine of the patients with prolonged ARF. All patients exhibited significant hyperreninemia when compared with normal euvolemic volunteers studied in our laboratory $(16.1 \pm 1.7$ vs. $0.6 \pm 0.2 \mathrm{ng} / \mathrm{ml}$ per h, $P$ $<0.001$ ). PRA levels were inversely related to both urine flow rate and inulin clearance (coefficients of correlation $=-0.70$ and -0.83 , respectively). There was also a weaker inverse rela-

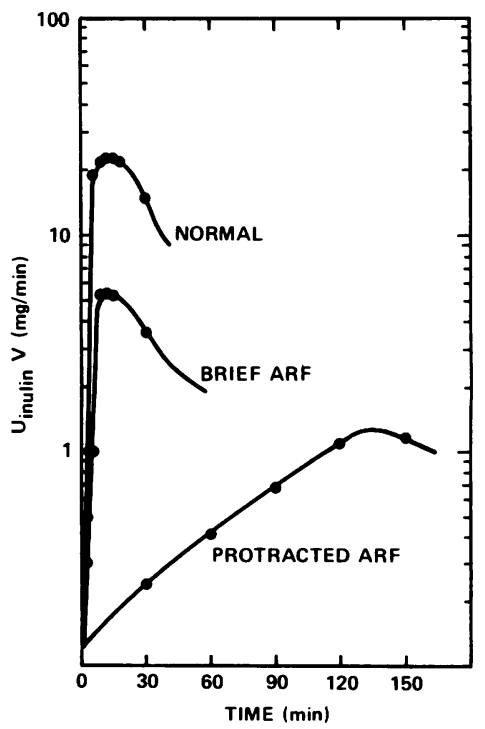

Figure 1. Urinary inulin excretion $\left(\mathrm{U}_{\text {inulin }} V\right)$ vs. time curves for 13 control patients with ARF of brief duration (middle) and 10 experimental patients with protracted ARF (bottom). The inulin excretion/time curve for normal postoperative subjects studied by us previously (10) is also shown for comparison (top). tionship to the rate of sodium excretion (coefficient of correlation $=-0.5)$.

Time to peak inulin excretion and $T_{u}$. As shown in Fig. 1, mean inulin excretion rate reached a maximum at $\sim 120 \mathrm{~min}$ in patients with protracted ARF. In comparison, subjects with ARF of brief duration (control group 1) achieved maximal excretion rates much earlier, at $\sim 11 \mathrm{~min}$, albeit at highly different maximal rates commensurate with renal function. The latter value is similar to that observed by us previously in postoperative subjects with normal renal function (10). The estimated urinary dead space volume $\left(U_{D S}\right)$ in patients with protracted ARF was smaller than that of brief ARF controls $(10 \pm 1.6$ vs. $15.6 \pm 2.0$ $\mathrm{ml}, P<0.05$ ). Further insight into the physiology of the urinary dead space may be obtained with the aid of the linear regression analysis depicted in Fig. 2, which demonstrates the relationship between urine flow rate $\dot{V}$ and $\mathrm{U}_{\mathrm{Ds}}$. As shown, $\mathrm{U}_{\mathrm{DS}}$ is directly related to $\dot{V}$ (coefficient of correlation $=0.7$ ). Thus, $\mathrm{U}_{\mathrm{Ds}}$ exhibits a kinetic compliance. Hence, with lower urine flow rates, as in subjects with prolonged ARF, $U_{D S}$ is also diminished. From the relationship in Fig. 2, it can be predicted that a minimal dead space volume of $6 \mathrm{ml}$ exists ( $3 \mathrm{ml}$ per kidney and ureter), even with complete anuria. ${ }^{2}$

The $T_{\mathrm{u}}$ was markedly increased in subjects with protracted ARF ( $80 \pm 45 \mathrm{~min})$, and greatly exceeded that of control patients with brief ARF $(9 \pm 1 \mathrm{~min}, P<0.01)$. However, $T_{\mathrm{u}}$ is directly proportional to the volume of the urinary dead space but inversely related to urine flow rate, i.e.,

2. Our findings are in keeping with an earlier study in the dog by Bojesen (20). He demonstrated both kinetic compliance and a similarly small volume of the dead space at low rates of urine flow in canine kidneys weighing $100-150 \mathrm{~g}$. Bojesen (20) validated the veracity of estimates of dead space volume from the kinetics of inulin excretion by making simultaneous direct determinations of pelvic volume over a wide range of urine flow rates. 


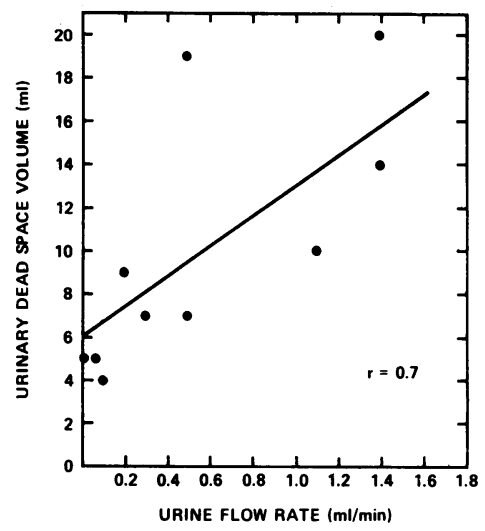

$T_{\mathrm{u}} \alpha\left(\mathrm{U}_{\mathrm{Ds}}\right) /(\dot{V})$.

Since $\mathrm{U}_{\mathrm{DS}}$ also declines as $\dot{V}$ decreases (Fig. 2), any prolongation of $T_{\mathrm{u}}$ caused by falling urine flow is to some degree abbreviated by the coincident reduction in $\mathrm{U}_{\mathrm{DS}}$.

Fractional inulin leakage. We have previously demonstrated the transtubular backleak of filtered inulin and dextran during ARF of brief duration $(11,12)$. In Fig. 3, the mean fractional dextran clearance profile for patients with protracted $\operatorname{ARF}\left(\theta_{\mathrm{ARF}}\right)$ is plotted as a function of the gel chromatographic radius of the dextran, $r_{\mathrm{D}}$, in the interval 17-40 $\AA$. For comparison, also depicted is the fractional dextran clearance profile of the 30 subjects of the second control group with stable $\operatorname{CRF}\left(\theta_{\mathrm{CRF}}\right)$. As shown, $\theta_{\mathrm{ARF}}$ is strikingly and significantly $(P<0.01)$ elevated above $\theta_{\mathrm{CRF}}$ for all dextran fractions in the $r_{\mathrm{D}}$ interval 17-40 $\AA$. Several points deserve additional emphasis: (1) $\theta_{\mathrm{CRF}}$ approaches but does not exceed unity for $r_{\mathrm{D}} 17-20 \AA(0.96 \leq \theta \leq 0.92)$; (2) $\theta_{\mathrm{CRF}}$ for larger dextran fractions $\left(r_{\mathrm{D}}>20 \AA\right)$ declines monotonically toward zero; (3) in striking contrast, only when $r_{\mathrm{D}}>28 \AA$ is $\theta_{\mathrm{ARF}}$ less than unity; (4) when a single patient (\#3), in whom there was no detectable backleak is excluded, $\theta_{\mathrm{ARF}}$ significantly exceeds unity for $r_{\mathrm{D}}=18 \AA$ and $19 \AA(P<0.05)$; and $(5)$ for $r_{\mathrm{D}}=17$ and $20 \AA<r_{D}<26 \AA, \theta_{A R F}$ also exceeds unity, although the difference fails narrowly to achieve statistical significance.

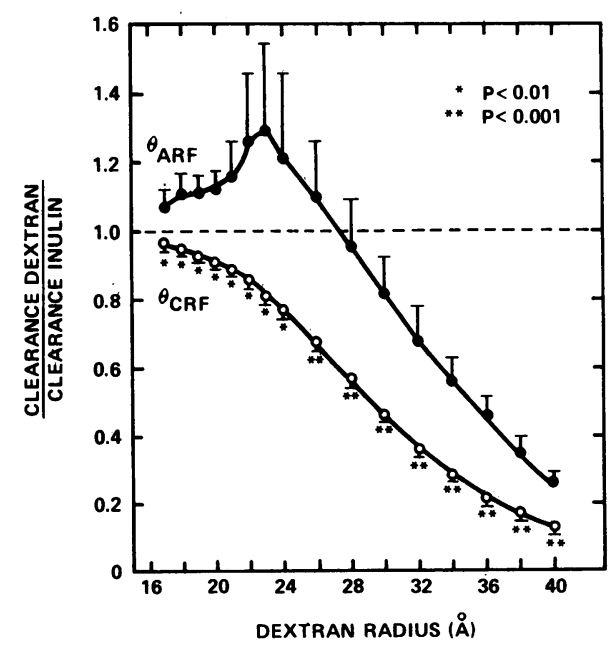

Figure 3. The mean fractional dextran clearance profile in 10 patients with protracted ARF (top) is compared with that of 30 control subjects with CRF (bottom). All results are expressed as mean \pm SE.
From Eq. 4, it may be calculated for the experimental population that $\sim 44 \%$ of filtered inulin emigrates from the tubular lumen (fractional inulin leakage, $k_{\text {in }}$ ) and thus fails to reach the final urine. Because of interpatient variability of fractional dextran clearance profiles for the protracted ARF studies, fractional inulin leakage was determined for each subject, with one exception. The value of $k_{\text {in }}$ was then used to correct those experimental variables affected by inulin backleak: inulin clearance, $T_{\max }$, and $T_{\mathrm{u}}$. Data are shown in Table IV. There was a single subject (\#3) who apparently had no backleak despite severe ARF. Otherwise, values for $k_{\text {in }}$ varied from 0.21 to 0.66 , reflecting considerable variability in the extent of increased tubular permeability, with the result that transtubular inulin leakage may differ more than threefold between individuals. In subject 6 , no inulin or dextrans were detected in the final urine despite the presence of both in plasma, which could theoretically reflect an extreme backleak of $100 \%$, i.e., $k_{\text {in }}=1$. (In the absence of measurable dextran and inulin clearances, however, actual fractional backleak cannot be calculated.) For nine patients, inulin clearances corrected for backleak varied from 0.4 to $27.9 \mathrm{ml} / \mathrm{min}$, averaging only 9.6 $\mathrm{ml} / \mathrm{min}$. Clearly, inulin backleak cannot wholly account for the grave reduction in GFR associated with protracted ARF. In these nine subjects, the time to peak inulin excretion, when corrected for backleak, was shortened from 120 to $102 \mathrm{~min}$. The $T_{\mathrm{u}}$ decreased from 33.8 to $20 \mathrm{~min}$. Even when corrected for transtubular inulin backleak, both the time to peak inulin excretion and the $T_{\mathrm{u}}$ are considerably prolonged when compared with corresponding values in the control population with brief ARF (Table IV).

Fractional dextran leakage. Not only filtered inulin leaks back from the damaged tubule, however. Were such to be true, then a fractional dextran clearance profile for the ARF population very different from that actually observed would be predicted. Fig. 4 displays the calculated fractional dextran clearance $\left(\theta_{\text {calculated }}\right)$ that would obtain if the tubule discriminated perfectly against molecules larger than inulin, so that approximately onehalf of filtered inulin, but no filtered dextran, were to escape the injured tubule. The hypothetical, calculated fractional clearance profile (top curve) represents therefore a twofold multiplication of control fractional dextran clearances (bottom curve). The fractional dextran clearance profile observed for protracted ARF (middle curve) clearly differs from both the upper and lower curves: it is elevated above the lower curve but depressed below the upper curve because both dextran and inulin leak back, although the percentage of inulin lost $\left(r_{\text {inulin }}=15 \AA\right)$ exceeds that of the larger dextran molecules. The difference between observed (o) and predicted ( $p$ ) curves reflects fractional dextran leakage $\left(k_{\mathrm{D}}=[\mathrm{p}-\mathrm{o}] / \mathrm{p}\right)$. As shown, the difference between the two curves varies continuously as $r_{\mathrm{D}}$ changes, declining as $r_{\mathrm{D}}$ increases.

The quantities $k_{\text {in }}$ and $k_{\mathrm{Di}}$ (where Di refers to an arbitrary dextran fraction of radius i) represent the individual rates of transport of inulin and the ith dextran across the damaged tubular epithelial barrier. The ratio $\left(k_{\mathrm{Di}} / k_{\text {in }}\right)$ may be taken, therefore, as a measure of the relative permeability of the epithelium to the $\mathrm{i}^{\text {th }}$ dextran with respect to inulin. An examination of $\left(k_{\mathrm{Di}} /\right.$ $k_{\text {in }}$ ) for dextrans in the radius interval $17-40 \AA$ is therefore instructive. The results of these calculations are plotted in Fig. 5. The accompanying fractional dextran clearance profile of the glomerulus in CRF ( $\theta_{\mathrm{CRF}}$, Fig. 3 ) is included for comparison. Relative to the glomerulus, it appears that the damaged tubule exhibits somewhat diminished permeability to dextrans of all 


\begin{tabular}{|c|c|c|c|c|c|c|c|}
\hline \multirow[b]{2}{*}{ Patient } & \multirow[b]{2}{*}{$k_{\mathrm{m}}$} & \multicolumn{2}{|l|}{$C_{\text {in }}$} & \multicolumn{2}{|l|}{$T_{\max }$} & \multicolumn{2}{|l|}{$T_{*}$} \\
\hline & & Raw & Corrected & Raw & Corrected & Raw & Corrected \\
\hline & & $\mathrm{ml} / \mathrm{min}$ & $\mathrm{ml} / \mathrm{min}$ & $\min$ & $\min$ & $\min$ & $\min$ \\
\hline 1 & 0.21 & 10.0 & 12.7 & 48 & 42 & 14 & 11 \\
\hline 2 & 0.57 & 12.0 & 27.9 & 90 & 60 & 38 & 16 \\
\hline 3 & 0 & 0.4 & 0.4 & 300 & 300 & 71 & 71 \\
\hline 4 & 0.55 & 8.0 & 17.8 & 30 & 27 & 9 & 5 \\
\hline 5 & 0.66 & 1.0 & 3.0 & 66 & 54 & 13 & 6 \\
\hline 7 & 0.58 & 1.0 & 2.4 & 300 & 240 & 90 & 38 \\
\hline 8 & 0.60 & 1.0 & 1.7 & 180 & 132 & 45 & 18 \\
\hline 9 & 0.59 & 2.0 & 4.9 & 54 & 42 & 14 & 6 \\
\hline 10 & 0.22 & 15.0 & 19.2 & 30 & 27 & 10 & 8 \\
\hline Mean* & 0.44 & 5.6 & $9 . \dot{6}$ & 120 & 102 & 33.8 & 20 \\
\hline$\pm \mathrm{SE}^{*}$ & \pm 0.06 & \pm 1.7 & \pm 3.0 & \pm 36 & \pm 30 & \pm 9 & \pm 7 \\
\hline \multicolumn{8}{|c|}{ Nonoliguric brief ARF controls $(n=13)$} \\
\hline Mean & 0.46 & 14.0 & 28.0 & 11 & 9 & 7 & 6 \\
\hline$\pm \mathrm{SE}$ & \pm 0.05 & \pm 2.0 & \pm 3.8 & \pm 1 & \pm 1 & \pm 1 & \pm 1 \\
\hline$P$ value & NS & $<0.01$ & $<0.01$ & $<0.001$ & $<0.001$ & $<0.01$ & $<0.01$ \\
\hline
\end{tabular}

${ }^{*} n=9$, because no inulin or dextran was detected in the urine of patient 6 up to $7 \mathrm{~h}$ after bolus despite adequate plasma levels. Calculation of fractional backleak for this patient was therefore not possible.

molecular sizes examined, and that the permeability declines at a rate (slope of the curve) which is similar to that of the glomerular sieving curve for $r_{\mathrm{D}}>24 \AA$. The relative tubular permeability is zero at $r_{\mathrm{D}} \geq 34 \AA$, even in the presence of a severe tubular injury. This finding provides an explanation for the observation in the rodent model of postischemic ARF that proteins of molecular radius $\geq 30 \AA$ cannot traverse the damaged tubular wall $(3,6)$.

Recovery of function after protracted $A R F .4$ of the 10 patients with sustained ARF recovered satisfactory renal excretory capacity. All survived (patients 1, 2, 4, and 10). The remaining six patients failed to recover renal function and each died. Data are summarized in Table V. Inulin clearance, though profoundly subnormal, was nonetheless greater in the subgroup that subsequently recovered $\left(11 \pm 1\right.$ vs. $1 \pm 0.3 \mathrm{ml} / \mathrm{min}$ per $\left.1.73 \mathrm{~m}^{2}\right)$. The superior rate of inulin clearance was further reflected by a lesser time to peak inulin excretion $(50 \pm 14$ vs. $170 \pm 60 \mathrm{~min})$. Those

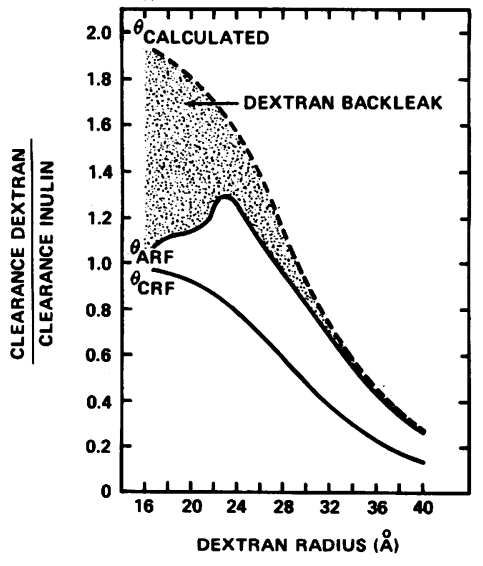

Figure 4. Fractional dextran clearance profile of control population with CRF (bottom), the hypothetical profile calculated as if one-half of filtered inulin but no dextran leaked from the tubule (top), and observed profile in subjects with protracted ARF (middle). who ultimately recovered satisfactory function had significantly higher urine flow rates, while those who exhibited no recovery were frankly oliguric $(1.1 \pm 0.2$ vs. $0.2 \pm 0.01 \mathrm{ml} / \mathrm{min})$. Commensurate with the urine flow, urinary dead space volumes also differed $(16 \pm 2$ vs. $7 \pm 1 \mathrm{ml})$. The combination of higher dead space volume but greater tubular flow nevertheless resulted in a shorter $T_{\mathrm{u}}(18 \pm 6$ vs. $47 \pm 13 \mathrm{~min}$ ). Patients who recovered also exhibited significantly less hyperreninemia $(2.3 \pm 0.3 \mathrm{vs.} 27.0 \pm 3.0 \mathrm{ng} / \mathrm{ml}$ per $h$ ). Thus, the extent of injury to the nephron in ARF may represent a graded response to the degree of underlying renal ischemia. As the latter increases in severity and duration, the manifest injury appears to advance through a brief form of ARF (control group 1) to a protracted, but reversible injury, or ultimately to an irreversible renal injury.

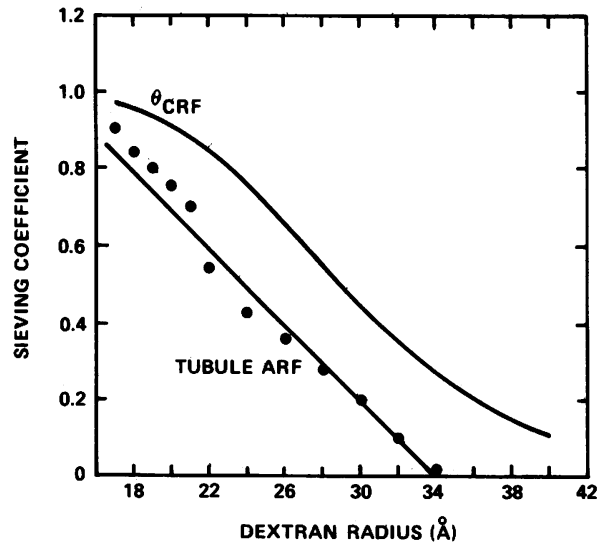

Figure 5. The dextran sieving behavior of the glomerular capillary wall in CRF (upper curve) is compared with that calculated for the damaged tubule in ARF (lower curve). 
Table V. Clinical and Biochemical Characteristics of Subjects Who Recovered vs. Failed to Recover Renal Function after Protracted ARF

\begin{tabular}{|c|c|c|c|c|c|c|c|c|c|c|c|}
\hline Recovery & & Age & $\begin{array}{l}\text { Sur- } \\
\text { vived }\end{array}$ & $\dot{V}$ & $\begin{array}{l}\mathrm{C}_{\mathrm{im}} \\
\left(\mathrm{ml} / \mathrm{min} / 1.73 \mathrm{~m}^{2}\right)\end{array}$ & $\mathrm{FE}_{\mathrm{Ne}_{\mathbf{e}}}$ & $\mathrm{U}_{\mathrm{DS}}$ & $k_{\text {in }}$ & $T_{\operatorname{mex}}$ & $T_{\mathrm{v}}$ & PRA \\
\hline & $n$ & & & $\mathrm{ml} / \mathrm{min}$ & & $\%$ & $m l$ & $\%$ & $\min$ & $\min$ & $n g / m l / h$ \\
\hline Yes & 4 & $58 \pm 7$ & 4 & $1.1 \pm 0.2$ & $11 \pm 1$ & $5.6 \pm 2$ & $16 \pm 2$ & $39 \pm 8$ & $50 \pm 14$ & $18 \pm 6$ & $2.3 \pm 0.3$ \\
\hline No & $6^{*}$ & $68 \pm 4$ & 0 & $0.2 \pm 0.1$ & $1 \pm 0.3$ & $10.1 \pm 5$ & $7 \pm 1$ & $49 \pm 10$ & $170 \pm 60$ & $47 \pm 13$ & $27.0 \pm 3.0$ \\
\hline$P$ value & & NS & $<0.05$ & $<0.01$ & $<0.01$ & NS & $<0.05$ & NS & $<0.01$ & $<0.05$ & $<0.01$ \\
\hline
\end{tabular}

${ }^{*} \mathrm{FE}_{\mathrm{Na}}, T_{\max }, T_{\mathrm{u}}$, and PRA: $\mathrm{n}=5$.

\section{Discussion}

Tubular obstruction. The severity of the renal injury sustained by the subjects of the current study is attested to by the loss of $96 \%$ of normal renal capacity to clear inulin from plasma. Furthermore, this impairment of function persisted on average for $5 \mathrm{wk}$, terminating either in recovery in a minority of patients or more often in the patients' demise. Compared with the results of previous studies from this laboratory, both the time to peak inulin excretion and $T_{\mathrm{u}}$ were markedly prolonged (10). Profound oliguria was also more frequently observed. These findings are similar to those of the maintenance phase of postischemic ARF in the rodent. In keeping with the more direct measurements in the rat (3-7), the prolongation of $T_{\mathrm{u}}$ in our patients may reflect significant tubular obstruction. In a prior study of nonoliguric postischemic ARF in man, in which measured renal impairment was less severe and of shorter duration, $T_{\mathrm{u}}$ was found to be normal (10). Given the demonstrated variability among individual nephrons of tubular obstruction in the rodent model (4, 5), a possible explanation for this finding was the existence of a small subpopulation of widely patent, unobstructed tubules (10). The existence of a sparse collection of tubules having unimpeded flow may be abetted by higher tubular fluid flow rates (signaled by nonoliguria); tubule cellular flotsam which would otherwise obstruct the tubular lumina could be literally washed away (10). The severe reduction in urine flow rate observed in our patients with protracted ARF may have reflected sluggish tubular fluid flow. This, in turn, could have contributed to more diffuse intratubular obstruction, and hence to the prolongation of both time to peak inulin excretion and $T_{\mathrm{u}}$. Thus, the threefold prolongation of $T_{\mathrm{u}}$ observed in the current study suggests the absence of completely patent tubules and the possibility of a much more homogeneous pattern of tubular injury. This finding is necessary, but insufficient by itself, to validate the concept that tubular obstruction may become generalized in this prolonged variant of human ARF.

Tubular leakage. The presence of transtubular backleak in our experimental subjects with protracted ARF is attested to by the finding of fractional dextran clearances that exceed unity, a phenomenon not observed in controls with CRF. Fractional dextran clearances in excess of unity must signify that either smaller inulin molecules leak back from the tubule with greater facility than larger dextrans, or that larger dextrans permeate the glomerular filter more easily than the smaller inulin molecule. It is difficult to conceive of any circumstance in which a larger molecule could by passive forces move more rapidly through the glomerular capillary wall than a smaller molecule. We infer, therefore, that the former explanation is correct and that there is in protracted ARF a size-dependent backleak of filtered molecules to which the tubule is normally impermeable.

From Eq. 3 we calculate that $k_{\text {in }}$, the fraction of filtered inulin that leaked back, was 0.44 , a finding in good agreement with the magnitude of inulin backleak in the rat with an analogous acute renal injury $(4,6,7)$. However, the calculation of $k_{\text {in }}$ rests upon the assumption that the Bowman's space-to-plasma concentration ratio (or glomerular sieving coefficient) of each dextran molecule in ARF does not differ from the corresponding value in the control population (group 2). Transcapillary dextran flux into Bowman's space is governed in part by the same determinants that control the ultrafiltration process. GFR in experimental ARF declines primarily because of a reduction in the net transmembrane ultrafiltration pressure $(4,8,21)$, while this latter quantity is elevated in CRF, in which GFR depression is caused by a reduction of the glomerular ultrafiltration coefficient, $K_{\mathrm{f}}(22)$. Despite these differences in the determinants of GFR in the two disorders, their net effect is to lower the filtration fraction. A lower filtration fraction will blunt the rise in concentration of a retained macromolecule as plasma transits along the glomerular capillaries (23), thereby lowering both diffusive and convective components of transcapillary dextran transport (19). Since the extent by which the filtration fraction is lowered in protracted ARF is unknown, the assumption of dextran sieving coefficients for the glomerulus identical to those in the CRF group (and hence our computation of $k_{\text {in }}$ ) may be in error. Accordingly, the corrected values for true GFR and mean residence time of inulin in the urinary dead space in protracted ARF (Table IV) should be regarded as approximations only.

Uncertainty regarding the actual value of $k_{\text {in }}$ also limits the precision with which the ratio $k_{\mathrm{Di}} / k_{\mathrm{in}}$ can be used to characterize the permselectivity of the damaged tubular wall in protracted ARF. In this case, moreover, it is necessary to make an additional assumption that the transport of inulin through the damaged tubular epithelial barrier in protracted ARF is unrestricted. Only in this latter circumstance can the ratio $k_{\mathrm{Di}} / k_{\text {in }}$ be regarded unequivocally as a sieving coefficient for the injured tubule. That inulin indeed passes through the injured tubular barrier in unrestricted fashion is suggested by the identity of its urinary clearance with that of DTPA. DTPA has a molecular weight of 393 daltons and a molecular radius of $\sim 4 \AA$. Inulin is heavier by tenfold and substantially larger (radius $=15 \AA$ ). Since both solutes are freely filtered across the glomerular capillary wall (24), the equality of their urinary clearances in the present study suggests that their respective rates of backleak across the injured tubular wall are not different. This implies that in ARF the transtubular transport of molecules the size of inulin or smaller is unrestricted. The ratio $k_{\mathrm{Di}} / k_{\mathrm{in}}$ can then be used to provide a 
reasonably accurate description of the size-selective properties of the tubular epithelial barrier. From the relationship between the ratio $k_{\mathrm{Di}} / k_{\text {in }}$ and dextran radius we infer that the injured tubular wall behaves as a membrane with a rather sharp cut-off, displaying almost complete impermeability to dextrans of radius above $34 \AA$. This membrane size-selectivity is in keeping with earlier observations in postischemic rodent ARF in which neither horseradish peroxidase $(r=30 \AA)$ nor albumin $(r=36 \AA)$ leaked back across the damaged tubular wall $(6,3)$.

The structure in the injured tubular wall most likely to behave as an effective barrier to the passage of macromolecules may be the tubular basement membrane. This collagenous structure has a composition not unlike that of the glomerular basement membrane. Thus, the similarity between the permselective properties of the damaged tubule in ARF and that of the glomerular capillary wall (Fig. 5) could be construed as pointing to the tubular basement membrane as the structure in protracted ARF that ultimately prevents the egress of dextrans of $34 \AA$ radius and larger from tubule fluid into the interstitium. The microdissection studies by Oliver and his coworkers (25) of individual nephrons from patients with protracted ARF are in keeping with this possibility. They observed a patchy detachment of necrotic tubular epithelial cells from the underlying tubular basement membrane, a phenomenon for which they coined the term tubulorrhexis. The denuded basement membrane remained intact, however, forming a continuous layer along the length of the necrotic tubule.

Recovery of function after $A R F$. In the rat, recovery from postischemic ARF has been presaged by increasing renal blood flow (8). Presumably restoration of their blood supply is necessary before necrotic tubular cells can regenerate. Because the ability of proximal tubular cells to secrete $p$-amino-hippuric acid is profoundly impaired during $\operatorname{ARF}(2,8,9)$, the clearance of $p$ amino-hippuric acid cannot be used to measure renal plasma flow in this circumstance. In the absence of an alternative, noninvasive method, we were unable to confirm the presence of renal underperfusion in the present study. That renal plasma flow in our patients with protracted ARF flow was severely depressed nonetheless, is suggested by the observation of extreme hyperreninemia. Similar elevations of active plasma renin levels by 20- or 30-fold have been observed by others during the oliguric phase of ARF. These levels have tended to decline as early oligoanuria gives way to the diuretic phase $(26,27)$. It may be that extreme elevations of PRA (and hence the vasoconstrictor angiotensin II) delay recovery from ARF. The findings in those subjects destined to recover of larger urine flow rates and greater inulin clearances coupled with less hyperreninemia are compatible with this view. In keeping with the finding that maneuvers that suppress the renin-angiotensin axis do not protect uniformly against subsequent ARF (28), hyperreninemia during ARF may be a secondary phenomenon, and its suppression may have importance only in facilitating the onset of recovery.

We conclude that the brief and protracted forms of ARF described in the present study represent a continuum of postischemic renal injury. Protracted ARF differs from the abbreviated injury in that the reductions in urine formation and inulin clearance are more profound. Even when corrected for backleak, the GFR is substantially lower in protracted than in brief ARF, $10 \pm 3$ vs. $28 \pm 4 \mathrm{ml} / \mathrm{min}$ per $1.73 \mathrm{~m}^{2}$, respectively. Clearly, factors other than backleak must be invoked to explain the disparity. More marked and diffuse intraluminal tubular obstruction in protracted ARF, with consequent reduction of the transmem- brane hydraulic pressure gradient, may be one such factor. A greater decline in glomerular perfusion rate due to extreme secondary hyperangiotensinemia may be another. We wish to emphasize, however, that there is at present no analogous animal model of greatly protracted ARF after prolonged and partial (and frequently repetitive) ischemic renal insults. Confirmation of the findings inferred from our necessarily indirect approach in human protracted ARF must await the development of a corresponding renal injury in experimental animals. Because of the lethal nature of protracted ARF in man, the development of an appropriate animal model is urgently required. Only by learning how to attenuate this severe form of ARF in the laboratory is an effective therapeutic strategy for the human renal injury likely to eventuate.

\section{Acknowledgments}

The authors thank Mary Peterson for ably preparing the manuscript.

This study was supported by grant 5 RO1 AM29985 from the National Institutes of Health. Dr. Moran's fellowship was supported jointly by the Marilyn Simpson Trust Foundation and by training grant AM 07357 from the National Institutes of Health.

\section{References}

1. Swann, R. C., and J. P. Merrill. 1953. The clinical course of acute renal failure. Medicine (Baltimore). 32:215-292.

2. Bull, G. M., A. M. Joeckes, and K. G. Lowe. 1950. Renal function studies in acute tubular necrosis. Clin. Sci. 9:379-404.

3. Tanner, G. A., K. L. Sloan, and S. Sophasan. 1973. Effects of renal artery occlusion on kidney function in the rat. Kidney Int. 4:377389.

4. Arendhorst, W. J., W. F. Finn, C. W. Gottschalk, and H. K. Lucas. 1976. Micropuncture study of acute renal failure following temporary renal ischemia in the rat. Kidney Int. 10(Suppl.):S100-S105.

5. Tanner, G. A., and S. Sophasan. 1976. Kidney pressures after temporary renal artery occlusion in the rat. Am. J. Physiol. 230:11731181.

6. Donohoe, J. F., M. A. Venkatachalam, D. B. Bernard, and N. G. Levinsky. 1978. Tubular leakage and obstruction after renal ischemia: structural-functional correlations. Kidney Int. 13:208-222.

7. Eisenbach, E. M., and M. Steinhausen. 1973. Micropuncture studies after temporary ischemia of rat kidneys. Pfluegers Arch. Eur. J. Physiol. 343:11-25.

8. Finn, W. F., and R. L. Chevalier. 1979. Recovery from postischemic acute renal failure in the rat. Kidney Int. 16:113-123.

9. Myers, B. D., C. Miller, J. Mehigan, C. Olcott, H. Golbetz, G. Derby, R. Spencer, and S. Friedman. 1984. Nature of the renal injury following total renal ischemia in man. J. Clin. Invest. 73:329-341.

10. Myers, B. D., B. J. Carrie, R. R. Yee, M. Hilberman, and A. S. Michaels. 1980. Pathophysiology of hemodynamically mediated acute renal failure in man. Kidney Int. 18:495-504.

11. Myers, B. D., F. Chui, M. Hilberman, and A. S. Michaels. 1979. Transtubular leakage of glomerular filtrate in human acute renal failure. Am. J. Physiol. 237:F319-F325.

12. Myers, B. D., M. Hilberman, B. J. Carrie, R. J. Spencer, and R. L. Jamison. 1982. Glomerular and tubular function in non-oliguric acute renal failure. Am. J. Med. 72:642-649.

13. Hilberman, M., B. D. Myers, B. J. Carrie, G. Derby, R. L. Jamison, and E. B. Stinson. 1979. Acute renal failure following cardiac surgery. J. Thorac. Cardiovasc. Surg. 77:880-888.

14. Johnston, P. A., D. B. Bernard, J. F. Donohoe, N. S. Perrin, and N. G. Levinsky. 1979. Effect of volume expansion on hemodynamics of the hypoperfused rat kidney. J. Clin. Invest. 64:550-558.

15. Anderson, R. J., and R. W. Schrier. 1980. Clinical spectrum of 
oliguric and non-oliguric acute renal failure. In Acute Renal Failure. B. M. Brenner and J. H. Stein, editors. Churchill Livingstone, Inc., New York. 1-17.

16. Anderson, R. J., S. L. Linas, A. S. Berns, W. L. Heinrich, T. R. Miller, P. A. Gabow, and R. W. Schrier. 1977. Non-oliguric acute renal failure. N. Engl. J. Med. 296:1134-1138.

17. Miller, T. R., R. J. Anderson, S. L. Linas, W. L. Heinrich, A. S. Berns, P. A. Gabow, and R. W. Schrier. 1978. Urinary diagnostic indices in acute renal failure. A prospective study. Ann. Intern. Med. 89:47-50.

18. Bryer-Ash, M., R. A. Ammon, and J. A. Luetscher. 1983. Increased inactive renin in diabetes mellitus without evidence of nephropathy. J. Clin. Endocrinol. Metab. 56:557-561.

19. Chang, R. L. S., C. R. Robertson, W. M. Deen, and B. M. Brenner. 1975. Permselectivity of the glomerular capillary wall to macromolecules. I. Theoretical considerations. Biophys. J. 15:861-906.

20. Bojesen, E. 1954. The transport of urine in the upper urinary tract. Acta Physiol. Scand. 32:39-62.

21. Oken, D. E. 1984. Hemodynamic basis for human acute renal failure (vasomotor nephropathy). Am. J. Med. 76:702-710.

22. Hostetter, T. H., H. G. Rennke, and B. M. Brenner. 1982. The case for intrarenal hypertension in the initiation and progression of diabetic and other glomerulopathies. Am. J. Med. 72:375-380.

23. Deen, W. M., C. R. Robertson, and B. M. Brenner. 1972. A model of glomerular ultrafiltration in the rat. Am. J. Physiol. 223:11781183.

24. Chervu, L. R., and M. D. Blaufox. 1982. Renal radiopharmaceuticals—an update. Semin. Nucl. Med. XII(3):224-245.

25. Oliver, J., M. MacDowell, and A. Tracy. 1951. Pathogenesis of acute renal failure associated with traumatic and toxic injury. J. Clin. Invest. 30:1305-1351.

26. Brown, J. J., R. L. Gleadle, D. H. Lawson, A. F. Lever, A. L. Linton, R. F. Macadam, E. Prentice, J. I. S. Robertson, and M. Tree. 1970. Renin and acute renal failure: studies in man. Brit. Med. J. 1:253258.

27. Tu, W. H. 1965. Plasma renin activity in acute tubular necrosis and other renal diseases associated with hypertension. Circulation. 31: 686-695.

28. Madias, N. E., and J. T. Harrington. 1983. Postischemic acute renal failure. In Acute Renal Failure. B. Brenner and J. M. Lazarus, editors. W. B. Saunders \& Co., Philadelphia. 235-251. 